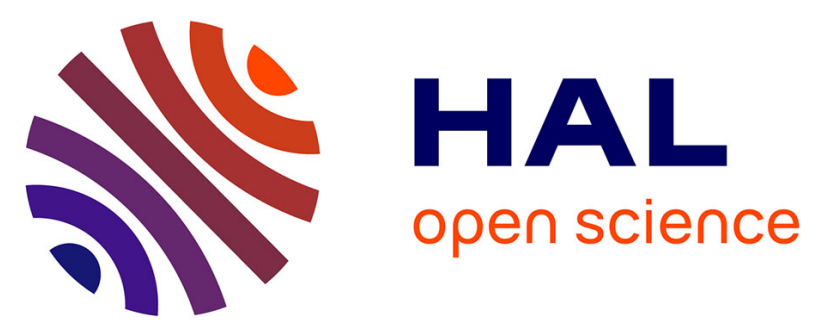

\title{
No evidence for change of the atmospheric helium isotope composition since 1978 from re-analysis of the Cape Grim Air Archive
}

J Mabry, Tf Lan, C Boucher, Christine Boucher, P.G. Burnard, M Brennwald, R Langenfelds, Bernard Marty

\section{To cite this version:}

J Mabry, Tf Lan, C Boucher, Christine Boucher, P.G. Burnard, et al.. No evidence for change of the atmospheric helium isotope composition since 1978 from re-analysis of the Cape Grim Air Archive. Earth and Planetary Science Letters, 2015, 10.1016/j.epsl.2015.07.035 . hal-01346175

\section{HAL Id: hal-01346175 \\ https://hal.science/hal-01346175}

Submitted on 22 Jul 2016

HAL is a multi-disciplinary open access archive for the deposit and dissemination of scientific research documents, whether they are published or not. The documents may come from teaching and research institutions in France or abroad, or from public or private research centers.
L'archive ouverte pluridisciplinaire HAL, est destinée au dépôt et à la diffusion de documents scientifiques de niveau recherche, publiés ou non, émanant des établissements d'enseignement et de recherche français ou étrangers, des laboratoires publics ou privés. 


\section{No evidence for change of the atmospheric helium}

\section{2 isotope composition since 1978 from re-analysis of}

3 the Cape Grim Air Archive

4

5 Jennifer C. Mabry ${ }^{1 *}$, Tefang Lan ${ }^{1 \$}$, Christine Boucher ${ }^{1}$, Peter G.

6 Burnard $^{1}$, Matthias S. Brennwald ${ }^{2}$, Ray Langenfelds ${ }^{3}$ and Bernard 7 Marty $^{1}$.

8

9 1: Centre de Recherches Pétrographiques et Géochimiques (CRPG-CNRS), 10 Université de Lorraine, BP20, 54501 Vandoeuvre-lès-Nancy Cedex, France

11 2: Eawag, Swiss Federal Institute of Aquatic Science and Technology, Department of Water Resources and Drinking Water, 8600 Dübendorf, Switzerland

3: Centre for Australian Weather and Climate Research / CSIRO Oceans and Atmosphere Flagship, Aspendale, Victoria, Australia

* Now at: Department of Earth Sciences, University of Oxford, OX1 3AN Oxford,

17 UK; Corresponding author: jennifer.mabry@earth.ox.ac.uk

\$Now at: Institute of Earth Sciences, Academia Sinica, 11529 Taipei, Taiwan 


\section{Abstract}

22 The helium isotope composition of air might have changed since the 23 industrial revolution due to the release of ${ }^{4} \mathrm{He}$-rich crustal helium

24 during exploitation of fossil fuels. Thereby, variation of the atmospheric 25 helium isotope ratio $\left({ }^{3} \mathrm{He} /{ }^{4} \mathrm{He}\right)$ has been proposed as a possible new 26 atmospheric tracer of industrial activity. However, the magnitude of 27 such change is debated, with possible values ranging from 0 to about 28 2\%o/yr (Sano, 1989; Hoffmann and Nier, 1993; Pierson-Wickmann et 29 al., 2001; Brennwald et al., 2013; Lupton and Evans, 2013). A new 30 analytical facility for high precision $(2 \%, 2 \sigma)$ analysis of the ${ }^{3} \mathrm{He} /{ }^{4} \mathrm{He}$ 31 ratio of air has been developed at CRPG Nancy (France) capable of 32 investigating permil level variations. Previously, Brennwald et al. 33 (2013) analyzed a selection of air samples archived since 1978 at

34 Cape Grim, Tasmania, by the Commonwealth Scientific and Industrial 35 Research Organisation (CSIRO). They reported a mean temporal 36 decrease of the ${ }^{3} \mathrm{He} /{ }^{4} \mathrm{He}$ ratio of $0.23-0.30 \% / \mathrm{yr}$. Re-analysis of aliquots 37 of the same samples using the new high-precision instrument showed 38 no significant temporal decrease of the ${ }^{3} \mathrm{He} /{ }^{4} \mathrm{He}$ ratio $(0.0095 \pm$ $390.033 \% \circ / y r, 2 \sigma)$ in the time interval 1978-2011. These new data 
constrain the mean $\mathrm{He}$ content of globally produced natural gas to

41 about $0.034 \%$ or less, which is about $3 \times$ lower than commonly quoted.

42

43

44 Introduction

45 The helium isotopic composition of air may be able to provide a new

46 tracer for studying and quantifying environmental changes resulting

47 from global warming and anthropogenic activity. Due to their light

48 masses, the two isotopes of helium escape to space through thermal

49 and non-thermal processes (Ozima and Podosek, 2002).

50 Consequently, the helium content of air is low (5.24 ppm vol.,

51 Gluckauf, 1946) and the atmospheric He isotope ratio is a transient

52 value determined by variations of the strengths of sources (outgassing

53 of the solid earth, extraterrestrial contributions) and sinks (loss to

54 space) of ${ }^{3} \mathrm{He}$ and of ${ }^{4} \mathrm{He}$ over time (Ozima and Podosek, 2002). The

55 He isotope residence time in the atmosphere is of the order of $10^{4}-10^{6}$

56 yr (Torgersen, 1989; Kockarts, 1973), much longer than the

57 atmospheric mixing time of $10 \mathrm{yr}$. Thus, the ${ }^{3} \mathrm{He} /{ }^{4} \mathrm{He}$ ratio of modern air

58 (1.34-1.40 x 10-6, Mamyrin et al., 1969; Clarke et al., 1975; Davidson

59 et al., 1988; Hoffmann and Nier, 1993; Sano et al., 1988) should be

60 constant on a decadal timescale. However, it has been suggested that 
61 this may no longer be the case (Sano, 1989; Pierson-Wickmann et al.,

62 2001; Brennwald et al., 2013; Lupton and Evans, 2013).

63 The exploitation of fossil fuels (coal, liquid and gaseous

64 hydrocarbons) may have released large amounts of ${ }^{4} \mathrm{He}$ during the

65 past couple of centuries and particularly the last few decades as

66 natural gas production has more than doubled between 1971 and

672012 (IEA, 2014). The recent rapid release of gases from these

68 reservoirs, which have concentrated crustal helium for tens to

69 hundreds of Ma, could have decreased the ${ }^{3} \mathrm{He} /{ }^{4} \mathrm{He}$ in the atmosphere

70 (Sano, 1989; Pierson-Wickmann et al., 2001; Brennwald et al., 2013).

71 Other anthropogenic extraction industries such as mining or quarrying

72 may also liberate unknown quantities of radiogenic $\mathrm{He}$ into the 73 atmosphere (Sano, 2010).

74 The only potential anthropogenic source of excess ${ }^{3} \mathrm{He}$ that could 75 increase the atmospheric ${ }^{3} \mathrm{He} /{ }^{4} \mathrm{He}$ ratio is $\mathrm{He}$ produced during induced $76 \mathrm{U}$ or $\mathrm{Pu}$ fission either in nuclear reactors or in nuclear weapons

77 (Lupton and Evans, 2004). However, anthropogenic nuclear He 78 sources can be relatively well quantified and do not contribute 79 significant He to the atmosphere (Lupton and Evans, 2004).

80 Studies on the atmospheric helium variations, summarized in 81 Brennwald et al. (2013) (e.g., compilation in their Table 1), resulted in 
82 contradictory results, indicating either decreases in the ${ }^{3} \mathrm{He} /{ }^{4} \mathrm{He}$ ratio of

83 the order of 0.1-0.3 \%o/yr during the last few decades (Sano et al.,

84 2010; Matsuda et al., 2010), or no detectable change since at least

851973 (Lupton and Evans, 2013) or possibly 1956 (Hoffmann and Nier, 86 1993).

87 The study of Brennwald et al. (2013) is particularly relevant, 88 because it presents results of temporal atmospheric helium variations 89 from samples periodically archived in stainless steel containers since 901978 (Cape Grim Air Archive (CGAA), Tasmania; Langenfelds et al., 91 1996). As these samples were collected from a single location, 92 Brennwald et al. (2013) argued that potential problems due to 93 geographical heterogeneities should not apply. Based on a statistical 94 analysis of repeated runs, Brennwald et al. reported a mean decrease 95 of the ${ }^{3} \mathrm{He} /{ }^{4} \mathrm{He}$ ratio of 0.23 to $0.30 \%$ o/yr during this period of time. In 96 contrast, Lupton and Evans (2013) did not observe any significant 97 difference between ${ }^{3} \mathrm{He} /{ }^{4} \mathrm{He}$ ratios measured in air samples taken at a 98 single location (La Jolla, California, USA) in 1973 and 2013. Together 99 with other data from different locations and periods of time, they 100 derived a mean rate of decrease of the ${ }^{3} \mathrm{He} /{ }^{4} \mathrm{He}$ ratio of $101(0.014 \pm 0.045) \% / \mathrm{yr}(2 \sigma)$, which is consistent with zero rate of change 102 over a 40-year period. 
104 that permits the analysis of the ${ }^{3} \mathrm{He} /{ }^{4} \mathrm{He}$ ratio of air with a precision for 105 individual measurements of about $2 \%$ (2б, Mabry et al., 2014) which 106 compares to about $14 \%$ ( $2 \sigma$, Brennwald et al., 2013). In order to 107 further investigate and better constrain the results reported by 108 Brennwald et al. (2013), we have analyzed aliquots of the same air 109 samples from the CGAA, as well as 5 further samples from years not 110 analyzed by Brennwald et al. (2013).

\section{Method}

The CGAA is a series of air samples collected typically every three

114 months since 1978 at Cape Grim on the north-west tip of Tasmania.

115 For each sample, 1-2 $\mathrm{m}^{3} \mathrm{STP}$ of air is collected and stored in 35-L 116 stainless steel tanks. The sampling and storage conditions of the air 117 samples were considered with great care to avoid 118 pollution/contamination from cities and industry during sampling or 119 modification of the sampled air during storage. This is necessary to 120 provide a true baseline air sample for the southern hemisphere that 121 could be used for many years. Details of the CGAA sampling 122 procedure are documented in Langenfelds et al. (1996) and Brennwald 123 et al. (2013). 
125 ten archive tanks spanning the time period $1978-2011: 1978,1979$, 126 1984, 1988, 1993, 1997, 2000, 2004, 2008, 2011 (Table 1). Multiple 127 subsamples were collected from each tank in 1.2-m-long, 3/8"-OD 128 copper tubes, which were sealed by cold-welding with a crimping tool 129 (Brennwald et al., 2013).

130 For measurement, a roughly 10 to $15 \mathrm{~cm}^{3}$ portion of the copper 131 tube is sealed off with a steel clamp and attached to the extraction line 132 using Swagelok Ultra-torr tube fittings and wrench-tightened. The 133 sample manifold is then evacuated, the pump isolated, and the copper 134 tube is opened to release the air sample into the extraction line for 135 purification and then measurement. A full description of the sample 136 processing and analysis is given in Mabry et al. (2013). Everything 137 aside from helium and neon is removed from the sample gas using a 138 series of getters and charcoal fingers. Then, the neon is separated 139 from helium using a cryo trap so that only the helium remains to be 140 admitted into the mass spectrometer. After purification of the sample, a 141 series of eleven standard-bracketed measurements are made. The 142 standard used for the bracketing measurements is derived from a 143 purified air standard collected from the Brittany coast. Note that this 144 standard $\mathrm{He}$ is enriched by $3.3 \%$ relative to the $\mathrm{He}$ isotope 
145 composition of air, as a result of isotope fractionation during handling 146 and purification of a large quantity of air. We attempted the purification 147 procedure twice and obtained the same fractionation. The cause of 148 this fractionation, possibly related to thermal effects between hot traps 149 and traps at liquid $\mathrm{N}_{2}$ temperature, are not fully elucidated. For our 150 purpose however, the absolute value of the running standard has no 151 bearing on the results (provided that its ${ }^{3} \mathrm{He} /{ }^{4} \mathrm{He}$ composition is close 152 to that of air), because all samples are normalized to this common 153 running standard and therefore can be inter-compared. In particular, 154 we continuously calibrate atmospheric helium from local air (Brabois 155 Park close to Nancy) against this standard (see below). Gas pressures 156 of the purified sample aliquots are matched to within $2 \%$ of the 157 standard aliquot pressures through the use of an adjustable volume in 158 order to eliminate pressure effects in the mass spectrometer.

159 Additionally, local air sampled in a park near CRPG (Brabois Air) is 160 analyzed periodically to compare all samples under the same analysis 161 and sampling conditions, and so, to monitor the continued efficacy of 162 the purification procedure and measurement stability. The measured $163{ }^{3} \mathrm{He} /{ }^{4} \mathrm{He}$ values of Brabois Air samples were very stable (standard 164 error $0.33 \%, 2 \sigma, N=83$ ) over a year of measurements (Mabry et al., 
2013) over the same time period the CGAA sample measurements were made.

\section{Results and Discussion}

\section{Helium in the Cape Grim Air Archive}

170 In Table 1, we report measurements from a selection of copper-

171 tube subsamples from the CGAA. Particular effort was made to make

172 multiple measurements from the earliest $(1978,1979)$ and latest

$173(2008,2011)$ subsamples since these would be the most likely to show

174 a detectable difference and would best constrain the trend over the 175 time period.

176 Three of the data points are statistically significant outliers. The $177{ }^{3} \mathrm{He} /{ }^{4} \mathrm{He}$ from 1988 and 2004 are $10-20 \%$ lower than all the other data 178 points, while the ${ }^{3} \mathrm{He} /{ }^{4} \mathrm{He}$ ratio of the 1984 subsample is about $4 \%$ 179 lower than in the other samples (excluding 1988 and 2004). A 180 generalized extreme Studentized deviate (GESD) test (Appendix A, 181 Rosner, 1983) confirms the 1988 and 2004 data points as outliers with $18299 \%$ confidence whether the test is run using the ratios or the 183 residuals of a best-fit linear time trend. This test assumes the dataset 
184 is approximately normally distributed which we confirmed by a normal 185 probability plot (not shown).

187 noted in Brennwald et al. (2013). The nitrogen isotopes in this 188 particular storage tank were detectably fractionated and additional 189 testing showed a change in the relative concentrations of $\mathrm{H}_{2}, \mathrm{CH}_{4}$, $190 \mathrm{CO}_{2}$, and $\mathrm{N}_{2} \mathrm{O}$ over time (Brennwald et al., 2013). These indicate a 191 small leak in this storage tank which would lead to a decrease in the $192{ }^{3} \mathrm{He} /{ }^{4} \mathrm{He}$ over time as slightly more ${ }^{3} \mathrm{He}$ effused out of the tank relative 193 to ${ }^{4} \mathrm{He}$, consistent with our data showing a lower ${ }^{3} \mathrm{He} /{ }^{4} \mathrm{He}$ ratio relative 194 to the other samples. We can correct for this effect using observed 195 changes in the concentrations of $\mathrm{H}_{2}, \mathrm{CH}_{4}, \mathrm{CO}_{2}$, and $\mathrm{N}_{2} \mathrm{O}$ and 196 Graham's Law to calculate the expected fractionation of the helium 197 isotopes (as in Brennwald et al., 2013). The correction increases the $1981984{ }^{3} \mathrm{He} /{ }^{4} \mathrm{He}$ by about $3.5 \%$, bringing it to well within the scatter of 199 the rest of the data excluding 1988 and 2004 (Table 1). Neither the 2001988 nor 2004 tanks at CSIRO show any evidence of leakage. Thus, it 201 seems likely that these samples were fractionated at some point after 202 subsampling, e.g., during storage or aliquoting of the subsamples. In 203 the following discussion, we will consider both the uncorrected and 204 effusion-corrected 1984 data but will exclude the 1988 and 2004 data. 
205 Table 1: Helium isotope ratios from different subsamples of the Cape Grim Air 206 Archive relative to our standard (R/Rstd) and then normalized to the overall mean 207 of the data. Where more than one measurement was made, the error-weighted 208 mean $(\bar{x})$ and the error of the mean is reported. Numbers in italics have been 209 identified as statistical outliers.

\begin{tabular}{|c|c|c|c|c|c|c|c|}
\hline \multicolumn{2}{|l|}{$\begin{array}{c}\text { Cape Grim } \\
\text { Archive Tank }\end{array}$} & R/Rstd & $2 \sigma$ & \multicolumn{2}{|l|}{$\begin{array}{c}\text { Cape Grim } \\
\text { Archive Tank }\end{array}$} & R/Rstd & $2 \sigma$ \\
\hline \multirow{3}{*}{$\begin{array}{c}7 \text { Jul } 1978 \\
(U A N 780002)\end{array}$} & & $\begin{array}{l}1.0035 \\
0.9992 \\
1.0026\end{array}$ & $\begin{array}{l}0.0020 \\
0.0020 \\
0.0022\end{array}$ & $\begin{array}{c}2 \text { Mar } 1993 \\
(U A N \text { 930279) }\end{array}$ & & 1.0009 & 0.0021 \\
\hline & & 0.9979 & 0.0024 & \multirow{2}{*}{$\begin{array}{c}7 \text { Jan } 1997 \\
(U A N 970008)\end{array}$} & & \multirow{2}{*}{0.9989} & \multirow{2}{*}{0.0021} \\
\hline & $\overline{\mathbf{x}}$ & 1.0009 & 0.0011 & & & & \\
\hline \multirow{5}{*}{$\begin{array}{c}6 \text { Feb } 1979 \\
(U A N 790001)\end{array}$} & & $\begin{array}{l}1.0015 \\
1.0003 \\
1.0001\end{array}$ & $\begin{array}{l}0.0020 \\
0.0022 \\
0.0021\end{array}$ & $\begin{array}{c}29 \text { Sep } 2000 \\
(U A N \text { 993562) }\end{array}$ & & 0.9988 & 0.0020 \\
\hline & & $\begin{array}{l}0.9992 \\
0.9997\end{array}$ & $\begin{array}{l}0.0020 \\
0.0023\end{array}$ & $\begin{array}{c}1 \text { Dec } 2004 \\
(U A N 997089)\end{array}$ & & 0.9885 & 0.0019 \\
\hline & & 0.9979 & 0.0023 & \multirow{4}{*}{$\begin{array}{c}12 \text { Aug } 2008 \\
(U A N \text { 999756) }\end{array}$} & & 1.0001 & 0.0023 \\
\hline & & 0.9997 & 0.0024 & & & 1.0006 & 0.0022 \\
\hline & $\overline{\mathbf{x}}$ & 0.9999 & 0.0008 & & & 0.9994 & 0.0022 \\
\hline \multirow{3}{*}{$\begin{array}{c}23 \text { May 1984 } \\
(U A N 840004)\end{array}$} & & 0.9963 & 0.0022 & & $\overline{\mathbf{x}}$ & 1.0000 & 0.0013 \\
\hline & & 0.9963 & 0.0022 & \multirow{6}{*}{$\begin{array}{c}4 \text { May } 2011 \\
(U A N \\
20110462)\end{array}$} & & 0.9990 & 0.0022 \\
\hline & $\overline{\mathbf{x}}$ & 0.9963 & 0.0016 & & & 0.9990 & 0.0020 \\
\hline \multicolumn{2}{|c|}{ Effusion corrected $\overline{\mathbf{x}}$} & 0.9997 & 0.0016 & & & 1.0007 & 0.0023 \\
\hline \multirow{3}{*}{$\begin{array}{c}21 \text { Jun } 1988 \\
(U A N 880003)\end{array}$} & & 0.9783 & 0.0020 & & & 1.0017 & 0.0022 \\
\hline & & 0.9771 & 0.0032 & & \multirow{2}{*}{$\overline{\mathbf{x}}$} & \multirow{2}{*}{1.0000} & \multirow{2}{*}{0.0011} \\
\hline & $\overline{\mathbf{x}}$ & 0.9780 & 0.0017 & & & & \\
\hline
\end{tabular}

210

211 An error-weighted least-squares fit (e.g. Baird, 1995) of the $212{ }^{3} \mathrm{He} /{ }^{4} \mathrm{He}$ with the uncorrected 1984 ratio (excluding 1988 and 2004) 213 results in a trend line with a slope that is essentially zero: $(0.000 \pm$ $2140.033) \% / \mathrm{yr}\left(2 \sigma\right.$, Fig 1b). If the potential effusion effect on the ${ }^{3} \mathrm{He} /{ }^{4} \mathrm{He}$ 215 value obtained from the 1984 tank is considered, the slope 
216 corresponds to a ${ }^{3} \mathrm{He} /{ }^{4} \mathrm{He}$ decrease of $(0.0095 \pm 0.033) \% / \mathrm{yr}(2 \sigma$, 217 Fig $1 b)$. The ${ }^{3} \mathrm{He} /{ }^{4} \mathrm{He}$ time series is therefore consistent with a constant $218{ }^{3} \mathrm{He} /{ }^{4} \mathrm{He}$ ratio and is constrained to a rate of decrease of less than $2190.033 \% / \mathrm{yr}$ ( $2 \sigma$, assuming no effusion) or $0.042 \% / \mathrm{yr}$ (considering the 220 potential effusion effect of the 1984 tank) during 1978-2011.

221 This contrasts with the measurements of the CGGA reported by 222 Brennwald et al. (2013) of a decrease of ${ }^{3} \mathrm{He} /{ }^{4} \mathrm{He}$ during 1978-2011 of $223 \quad(0.23-0.30 \pm 0.16) \% / \mathrm{yr}(2 \sigma$, Fig $1 \mathrm{~b})$. Although Brennwald et al. find 224 that their data are, in a statistical sense, more likely to be explained by 225 a linear decrease than by a constant ${ }^{3} \mathrm{He} /{ }^{4} \mathrm{He}$, their data does not rule 226 out the possibility of a constant ${ }^{3} \mathrm{He} /{ }^{4} \mathrm{He}$ per se. The new measurement 227 method used here yields much less scatter of the data for replicate 228 analyses of the same subsample as compared to those reported in 229 Brennwald et al. (Fig 1a). The data of this work and Brennwald et al. 230 do overlap at the 20-level (Fig 1b) and thus taken together are 231 consistent with no statistically significant change in the helium isotopes 232 of the Cape Grim Air Archive over the measured time period, but the 233 new data better constrain the upper limit of possible change. 234 Furthermore, this result is in good agreement with recently published 235 data by Lupton and Evans (2013), who report no significant change in 
236 the helium isotopic ratio (Fig 1b) in air over the last few decades and a 237 maximum possible decrease of ${ }^{3} \mathrm{He} /{ }^{4} \mathrm{He}$ of $0.059 \% / \mathrm{yr}(2 \sigma)$. 
238 Figure 1: (a) The individual ${ }^{3} \mathrm{He} /{ }^{4} \mathrm{He}$ values from replicate analyses reported in Brennwald et al. 2392013 (solid circles) and those measured in this work (open squares). Data are normalized to the 240 mean value of each respective data set to allow for direct comparison. (b) Shows the error241 weighted means of the individual replicate measurements on subsamples. The effusion corrected 2421984 mean is shown with an open diamond. The error-weighted best-fit lines are shown for 243 Brennwald et al. 2013 (dashed line), this work with 1984 effusion corrected (solid line) and 244 uncorrected (dotted line). Also shown for comparison are data from Lupton and Evans (2013, solid 245 triangles). All errors are $2 \sigma$.

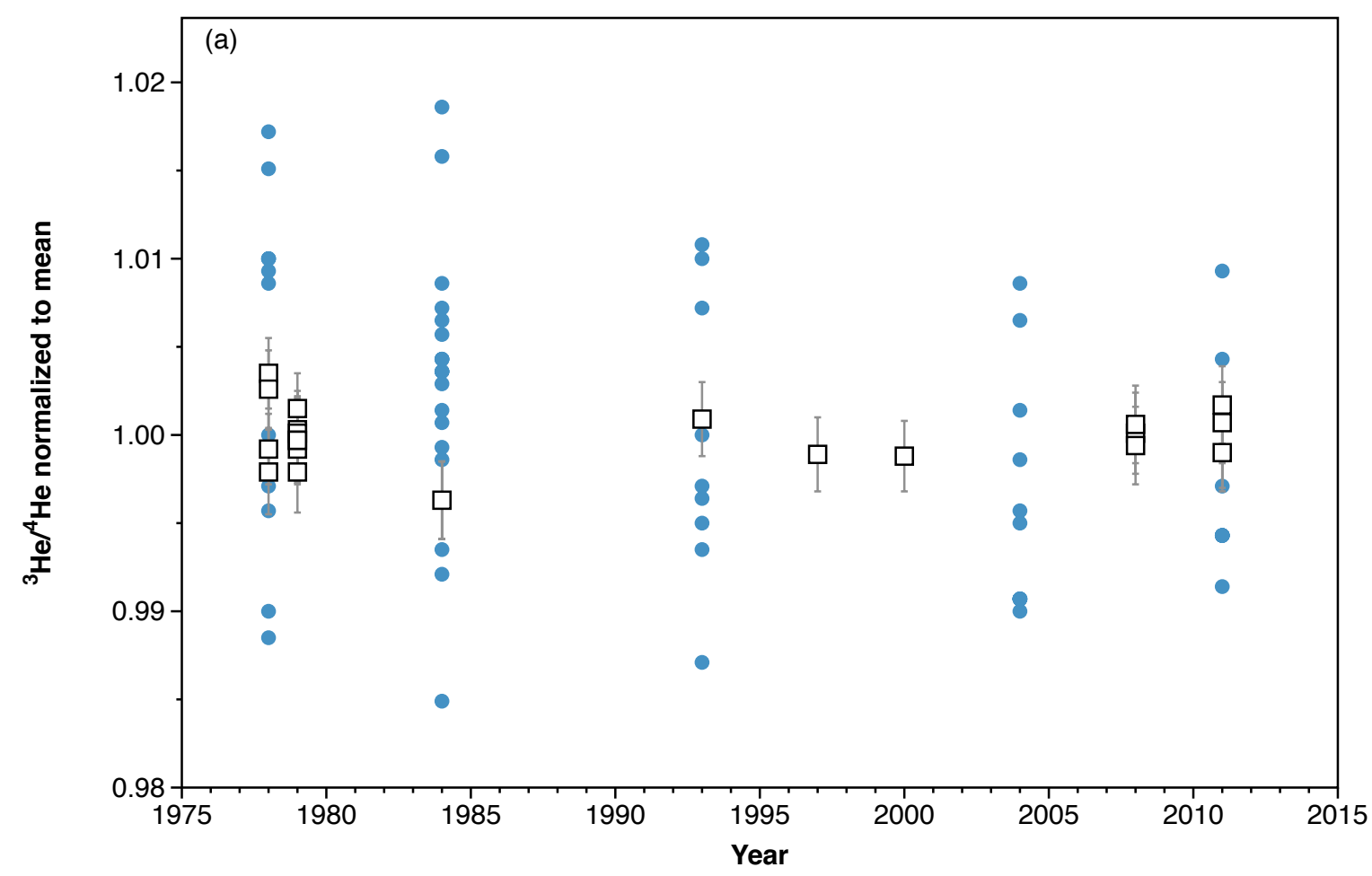




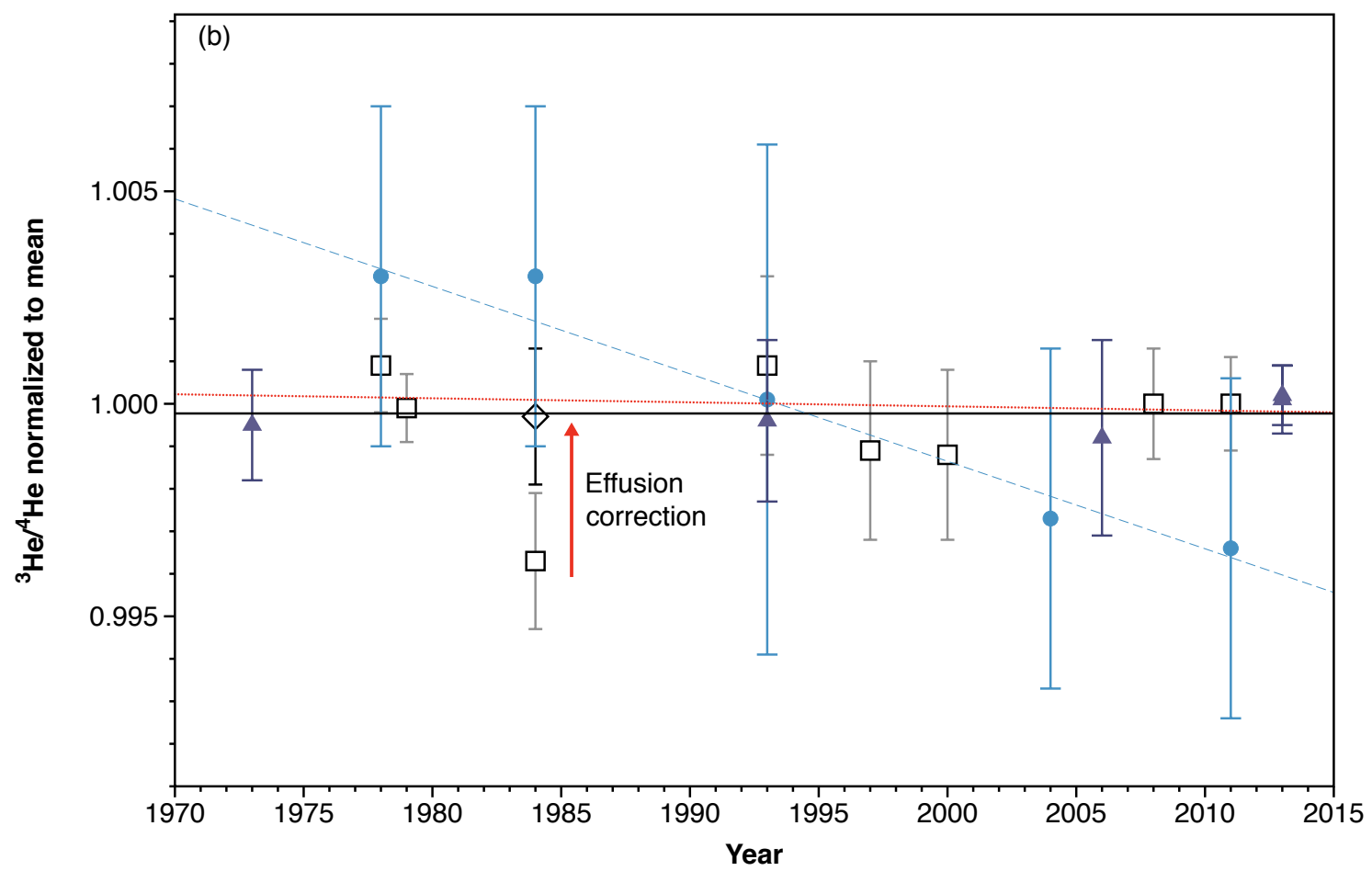

247 samples and did not observe any significant trend if the uncorrected 2481984 data are excluded. If the change in helium isotopic ratio were due 249 to excess ${ }^{4} \mathrm{He}$ released into the atmosphere as theorized, this should 250 manifest also as an increasing $\mathrm{He} / \mathrm{Ne}$ ratio over the same time period. 251 The fact that they saw no change in this ratio was at odds with their 252 helium isotope data, but is consistent with the new measurements in 253 this work.

\section{Helium in natural gas}

The constancy of the ${ }^{3} \mathrm{He} /{ }^{4} \mathrm{He}$ ratio over the last few decades is 256 inconsistent with available estimates for He isotope fluxes during this 257 period, which predict a decrease of the ${ }^{3} \mathrm{He} /{ }^{4} \mathrm{He}$ ratio of about $0.1 \%$ o $/ \mathrm{yr}$ 
(Sano, 2010). These predictions are dependent on the global average

259 He content of natural gas, which has been estimated to be $0.1-0.25 \%$ 260 (Oliver et al., 1984). However, barring a credible source of excess ${ }^{3} \mathrm{He}$, 261 the data sets from this work and Lupton and Evans (2013) point to this 262 being a significant overestimation of the mean helium content in 263 natural gas produced globally.

264 These predicted He concentrations come primarily from the U.S. 265 Bureau of Land Management's (previously Bureau of Mines) survey of 266 natural gas compositions (see e.g BLM, 2008). A straight average of 267 the helium compositions contained in this database yield an average 268 helium content of around $0.25-0.3 \%$. However, Lupton and Evans 269 (2013) noted that this data shows an inverse correlation between 270 helium content and reported production rate (open flow) of the well, 271 indicating that there may be an inverse relationship between helium 272 content and field size. Weighting the helium data by open flow brings 273 the average down to around $0.15 \%$. Additionally, this database may 274 over-represent higher helium wells since it includes primarily data from 275 U.S. wells ( 16,700 U.S. records vs 133 non-U.S.) which may have a 276 higher helium content then the rest of the world (non-U.S. average 277 helium content $\sim 0.06 \%$ ). And this database may even over-sample 278 higher helium wells within the U.S. as well since helium is an important 
279 commodity. These factors suggest that the true average helium 280 composition is likely less than $0.15 \%$.

281 If we look directly at helium production, Mohr and Ward (2014) 282 estimate that $\sim 2.0 \times 10^{11}$ moles were produced world wide between 2831921 and 2012. Assuming most of this helium made its way into the 284 atmosphere within a few years, it would lead to a decrease in the 285 atmospheric ${ }^{3} \mathrm{He} /{ }^{4} \mathrm{He}$ of about $0.0025 \%$ o/yr (or about $0.225 \%$ over the 286 91-year span). Narrowing the focus to just the period 1978-2011, we 287 have about $1.5 \times 10^{11}$ moles produced world wide (U.S. Geological 288 Survey, 2014), leading to a decrease in the atmospheric ${ }^{3} \mathrm{He} /{ }^{4} \mathrm{He}$ of 289 about $0.005 \%$ o/yr (or about $0.15 \%$ o over the 33-year span). If we further 290 assume that helium is being extracted from most of the high-helium 291 natural gas wells, then the average helium content for the remaining 292 wells would be much lower. After accounting for helium production and 293 using an average natural gas production over the last three decades of $294 \sim 1 \times 10^{14} \mathrm{~mol} / \mathrm{yr}($ IEA, 2014), then we find the average helium content

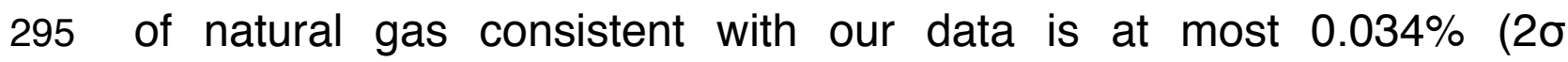
296 maximum). This is roughly $3-7 \times$ lower than the commonly quoted 297 values of $0.1-0.25 \%$.

298

299 Conclusion 
We have re-analyzed the $\mathrm{He}$ isotope composition of a series of air 301 aliquots sampled at Cape Grim, Tasmania, and stored in stainless 302 steel taken by CSIRO. We do not observe any significant change in 303 the ${ }^{3} \mathrm{He} /{ }^{4} \mathrm{He}$ ratio over this time period and find the maximum rate of

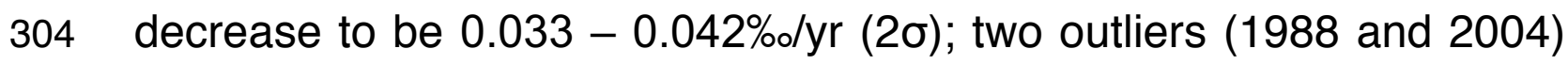
305 have been excluded from the compilation. We do not reproduce the 306 result of Brennwald et al. (2013), who, based on the analysis of air 307 aliquots from the same series reported a decrease of $(0.23-0.30 \pm$ $3080.16) \% / \mathrm{yr}$ of the ${ }^{3} \mathrm{He} /{ }^{4} \mathrm{He}$ ratio between 1978 and 2011 . Our results 309 are consistent with previous reports that the He isotope composition of 310 air has not changed by more than $0.059 \%$ o/yr $(2 \sigma)$ between 1973 and 3112013 (Lupton and Evans, 2013), and with the results of Hoffmann and 312 Nier (1993) who concluded there was no significant change in the $313{ }^{3} \mathrm{He} /{ }^{4} \mathrm{He}$ ratio based on measurements done on air collected between 3141956 and 1988. Our data suggests that the commonly reported mean 315 concentration of helium in natural gas is significantly over-estimated 316 (at least $3 \times$ ) and is likely no more than $0.034 \%$.

317 Given the inconsistency of reported atmospheric ${ }^{3} \mathrm{He} /{ }^{4} \mathrm{He}$ trends in 318 the literature, the discrepancy in measurements of the same CGAA 319 samples reported here and by Brennwald et al. (2013), and the 320 unexplained fractionation of the 1988 and 2004 samples, it is proposed 
321 that a new subset of CGAA samples should be prepared by CSIRO 322 and analyzed at CRPG. These samples will be filled in stainless steel 323 flasks with valves, rather than the copper tubes used previously, and 324 will extend the time series to at least 2015.

325

\section{Acknowledgments}

327 This project has been funded by the French Agence Nationale de la Recherche 328 (Project VIHA2) and by the European Research Council under the European 329 Community's Seventh Framework Programme (FP7/2010-2016 grant agreement 330 no. 267255). The Deep Carbon Observatory also provided funding support. We 331 acknowledge the CSIRO and Cape Grim Baseline Air Pollution Station staff who 332 assisted with collection, analysis and maintenance of the CGAA samples, and Dr. 333 Paul Steele for helpful discussions relating to this work. Thanks also to helpful 334 comments from two anonymous reviewers, and to Editor Derek Vance.

335

336 Appendix A: Generalized ESD test

337 For a data set which is approximately normally distributed, with mean $(\bar{x})$ and 338 standard deviation $(\sigma)$ the generalized extreme Studentized deviate (GESD) test 339 (Rosner, 1983) can detect multiple outliers. The test null hypothesis is that there 340 are no outliers in the data set, and the alternate hypothesis is that there are up to $r$ 341 outliers. The test statistic $\left(R_{i}\right)$

$$
R_{i}=\frac{\max _{i}\left|x_{i}-\bar{x}\right|}{\sigma}
$$


343 is calculated for the most extreme outlier first (maximum $\left|x_{i}-\bar{x}\right|$ ), and then that

344 data point $\left(x_{i}\right)$ is removed and the test statistic is recalculated until all potential 345 outliers have been removed.

After calculating the test statistic for each potential outlier $\left(R_{1}, R_{2}, \ldots, R_{r}\right)$,

347 the critical values can be calculated for significance level a:

348

$$
\lambda_{i}=\frac{(n-i) t_{p, n-i-1}}{\sqrt{\left(n-i-1+t_{p, n-i-1}^{2}\right)(n-i+1)}} i=1,2, \ldots, r
$$

349 where

$$
p=1-\frac{\alpha}{2(n-i+1)}
$$

351

352 and $t_{p, v}$ represents the pth percentile of a t distribution with $v$ degrees of freedom.

353 The number of outliers is determined by finding the largest $i$ such that $R_{i}>\lambda_{i}$.

\section{References}

356 Baird, D.C., 1995. Experimentation: An Introduction to Measurement Theory and 357 Experiment Design, 3rd ed. Prentice-Hall, Englewood Cliffs, New Jersey.

358 Brennwald, M.S., Vogel, N., Figura, S., Vollmer, M.K., Langenfelds, R., Paul Steele, L., 359 Maden, C., Kipfer, R., 2013. Concentrations and isotope ratios of helium and other 360 noble gases in the Earth's atmosphere during 1978-2011. Earth Planet. Sci. Lett. 361 366, 27-37. doi:10.1016/j.epsl.2013.01.039

362 BLM, 2008. Analyses of natural gases, 1917- October 2008, U.S. Bureau of Mines 363 Publication PB2009500006, National Technical Information Service, Alexandria, VA. 
Clarke, W.B., Jenkins, W.J., Top, Z., 1976. Determination of tritium by mass spectrometric measurement of 3He. Int. J. Appl. Radiat. Isot. 27, 515-522. doi:10.1016/0020708X(76)90082-X

367

Davidson, T.A., Emerson, D.E., 1990. Direct Determination of the Helium 3 Content of Atmospheric Air by Mass Spectrometry. J. Geophys. Res. 95, 3565-3569.

Gluckauf, E., 1946. A Micro-Analysis of the Helium and Neon Contents of Air. Proc. R. Soc. A Math. Phys. Eng. Sci. 185, 98-119. doi:10.1098/rspa.1946.0007

Hoffman, J.H., Nier, A.O., 1993. Atmospheric Helium Isotopic Ratio. Geophys. Res. Lett. 20, 121-123. doi:10.1002/jms.1057

IEA, 2014. Key world energy statistics 2014, International Energy Agency, Paris.

374 (Available at https://www.iea.org/publications/freepublications/publication/KeyWorld2014.pdf)

Kockarts, G., 1973. Helium in the terrestrial atmosphere. Space Sci. Rev. 14, 723-757.

377

378

379

380

381

382

383

384

Langenfelds, R.L., Fraser, P.J., Francey, R.J., Steele, L.P., Porter, L.W., Allison, C.E., 1996. The Cape Grim Air Archive: the first seventeen years, 1978-1995, in: Baseline 94-95. Bureau of Meteorology and CSIRO Division of Atmospheric Research, Melbourne, pp. 53-70.

Lupton, J., Evans, L., 2004. The atmospheric helium isotope ratio: Is it changing? Geophys. Res. Lett. 31, 4. doi:L13101 10.1029/2004gl020041

Lupton, J., Evans, L., 2013. Changes in the atmospheric helium isotope ratio over the past 40 years. Geophys. Res. Lett. 40, 6271-6275. doi:10.1002/2013GL057681

385 Mabry, J., Lan, T., Burnard, P., Marty, B., 2013. High-precision helium isotope 
Mamyrin, B.A., Anufriev, G.S., Kamenskii, I.L., Tolstikhin, I.N., 1970. Determination of the isotopic composition of atmospheric helium. Geochem. Int. (Engl. Transl.) 7, 498-

389 505.

390

Matsuda, J.-I., Matsumoto, T., Suzuki, A., 2010. Helium in old porcelain: The historical variation of the He isotopic composition in air. Geochem. J. 44, e5-e9.

Mohr, S., Ward, J., 2014. Helium Production and Possible Projection. Minerals 4, 130 393 144. doi: $10.3390 / \min 4010130$

394 Oliver, B.M., Bradley, J.G., Farrar IV, H., 1984. Helium concentration in the Earth's lower 395 atmosphere. Geochim. Cosmochim. Acta 48, 1759-1767.

396

Ozima, M., Podosek, F.A., 2002. Noble Gas Geochemistry, 2nd ed. Cambridge University 397 Press.

398

Pierson-Wickmann, A.-C., Marty, B., Ploquin, A., 2001. Helium trapped in historical slags:

399 a search for temporal variation of the He isotopic composition of air. Earth Planet. Sci.

400 Lett. 194, 165-175.

401

Rosner, B, 1983. Percentage Points for a Generalized ESD Many-Outlier Procedure, $402 \quad$ Technometrics, 25(2), 165-172.

403 Sano, Y., Furukawa, Y., Takahata, N., 2010. Atmospheric helium isotope ratio: Possible 404 temporal and spatial variations. Geochim. Cosmochim. Acta 74, 4893-4901. 405 doi:10.1016/j.gca.2010.06.003

406 Sano, Y., Wakita, H., 1988. Precise measurement of helium isotopes in terrestrial gases. $407 \quad$ Bull. Chem. Soc. Jpn. 61, 1153-1157. 
408 Sano, Y., Wakita, H., Makide, Y., Tominaga, T., 1989. A ten-year decrease in the 409 atmospheric helium isotope ratio possibly caused by human activity. Geophys. Res.

$410 \quad$ Lett. 16, 1371-1374. doi:10.1029/GL016i012p01371

411 Torgersen, T., 1989. Terrestrial helium degassing fluxes and the atmospheric helium

412 budget: Implications with respect to the degassing processes of continental crust.

413 Chem. Geol. Isot. Geosci. Sect. 79, 1-14. doi:10.1016/0168-9622(89)90002-X

414 U.S. Geological Survey, 2014. Helium statistics (through 2013; last modified 30 January

415 2015), in Kelly, T.D., and Matos, G.R., comps., Historical statistics for mineral and

416 material commodities in the United States (2013 version): U.S. Geological Survey

417 Data Series 140, accessed 28 June 2015, at

418 http://minerals.usgs.gov/minerals/pubs/historical-statistics/.

419

420 